\title{
Appendicular Peritonitis in the General Surgery Department of Gabriel TOURE CHU
}

\author{
Maïga Amadou1 ${ }^{*}$, Diakité Ibrahima², Bah Amadou' ${ }^{2}$, Diallo Aly Boubacar'1, Traoré Bathio1, \\ Moussa Diassana ${ }^{1}$, Sidibé Boubacar Yoro ${ }^{2}$, Koné Tani' ${ }^{2}$, Doumbia Arouna Adama' ${ }^{2}$, \\ Traoré Amadou2, Saye Zakari², Saadé Oumou Hélène², Kanté Lassana ${ }^{2}$, Konaté Madiassa2, \\ Dembélé Souleymane², Samaké Moussa², Dembélé Bakary Tientigui², Traoré Alhassane², \\ Togo Adégné 2
}

\author{
${ }^{1}$ Service de chirurgie générale, Hôpital de Sikasso, Sikasso, Mali \\ ${ }^{2}$ Service de chirurgie générale, CHU Gabriel Touré, Bamako, Mali \\ Email: ^amadoumaiga3@gmail.com
}

How to cite this paper: Amadou, M., Ibrahima, D., Amadou, B., Boubacar, D.A., Bathio, T., Diassana, M., Yoro, S.B., Tani, K., Adama, D.A., Amadou, T., Zakari, S., Hélène, S.O., Lassana, K., Madiassa, K., Souleymane, D., Moussa, S., Tientigui, D.B., Alhassane, T. and Adégné, T. (2022) Appendicular Peritonitis in the General Surgery Department of Gabriel TOURE CHU. Surgical Science, 13, 9-14.

https://doi.org/10.4236/ss.2022.131002

Received: November 3, 2021

Accepted: January 7, 2022

Published: January 10, 2022

Copyright $\odot 2022$ by author(s) and Scientific Research Publishing Inc. This work is licensed under the Creative Commons Attribution International License (CC BY 4.0).

http://creativecommons.org/licenses/by/4.0/

\begin{abstract}
The appendicular peritonitis is complications of acute appendicitis which are characterized by the diffusion of the infectious process to the peritoneal cavity thus carrying out a generalized or located purulent peritonitis. It can appear from the start or follow the stage of appendicular abscess. Our objectives were to determine the frequency, to describe the clinic and para clinic aspects, to identify the principal germs and their sensitivities to antibiotics and to describe the operative continuations. Our prospective and descriptive study focused on patients treated for appendicular peritonitis, from January $1^{\text {st }}$ to December $31^{\text {st }}$ 2016, in the General Surgery Department of the Hospital of Sikasso. During the period of our study, 31 cases of appendicular peritonitis were collected, which represented $4.36 \%$ of surgical interventions, $19.25 \%$ of urgent surgeries. The male sex accounted for $71.0 \%$ with a sex-ratio of 2.44 at the risk of males, the average age was of 20 years \pm 12.99 , the abdominal pain + vomiting was the reason for consultation in $54.8 \%$ of cases. The physical examination allowed in most cases to make the diagnosis. In doubtful cases some additional examinations have been requested (abdomen without preparation, abdominal ultrasound). The surgical treatment consisted of an appendectomy with peritoneal lavage followed by drainage. The average length of hospital stay was 8.8 days with extremes of 1 - 44 days. Hospital mortality was 9.7\%. Delay in consultation and age were factors of morbidity and high mortality.
\end{abstract}

\section{Keywords}

Appendicular Peritonitis, Surgical Emergencies, Hospital of Sikasso 


\section{Introduction}

Appendicular peritonitis is complications of acute appendicitis characterized by the spread of the infectious process to the peritoneal cavity, thus producing generalized or localized purulent peritonitis. It can appear immediately or follow the stage of appendicular abscess [1].

Perforation is the rupture of the wall of the appendix putting its septic contents in communication with the peritoneal cavity [2].

Peritonitis is a medical-surgical emergency because the prognosis can be serious (depends on the patient's age, his general condition and associated defects, the etiology and the delay in surgical management).

Despite effective health coverage in the West, the incidence of appendicular peritonitis does not decrease (20/100,000/year) [3].

Numerous studies carried out on peritonitis caused by digestive perforations [4] [5] [6] [7] have shown the predominance of appendicular perforations.

Flum D.R. et al. [8] in the USA in 2001 in a retrospective study on 63,707 appendectomies, found $25.85 \%$ of peritonitis by appendicular perforation.

In Europe: Kraemer, M. [9] in 2003 in a prospective multicenter study in 11 surgical departments in Germany and Austria on 519 cases of appendicitis, found $17.7 \%$ of peritonitis by appendicular perforations.

In Africa: Chavda S.K. [10] in Kenya in 2005 in a retrospective and descriptive study of 289 patients managed for suspected appendicitis found $29.7 \%$ of cases of appendicular perforation with morbidity of $19.4 \%$ and zero mortality.

In Mali: Numerous studies have shown the predominance of appendicular perforations in digestive perforations.

Camara B. [4] in 2008 in a retrospective study at the CHU Gabriel Touré found 137 cases of appendicular peritonitis constituting 33.25\% of acute generalized peritonitis with $15.3 \%$ of complications and a mortality rate of $0.7 \%$.

\section{Goals}

Describe the epidemiological, therapeutic and evolutionary aspects, identify the main germs and their sensitivity to antibiotics.

\section{Methodology}

This was a 12-month prospective and descriptive study from January 1, 2016 to December 31, 2016, in the general surgery department of Gabriel TOURE CHU.

All patients operated on for peritonitis whose etiology was appendicular intraoperatively.

All non-appendicular peritonitis and all patients operated outside the ward were not included in the study.

\section{Results}

During the study period we collected 31 files of appendicular peritonitis which represented $4.36 \%$ of surgical interventions, $2.99 \%$ of hospitalizations, $19.25 \%$ of 
emergency surgical interventions, $52.54 \%$ of acute peritonitis generalized. The mean age of the patients was 20.42 years with extremes of 4 years and 58 years and a standard deviation of 12.99 . The sex ratio was 2.44. Abdominal pain was the main reason for consultation in all of our patients. The average consultation time is 5.7 days, with extremes of 1 and 12 days. Treatment (traditional + medical) was carried out by 17 patients (54.8\%). The most common physical signs are summarized in Table 1.

We performed 28 ultrasounds which demonstrated 16 times a cloudy effusion (51.6\%), 5 times a thickening of the appendix (16.1\%), a cloudy effusion plus a lesion of the appendix in 6 cases, i.e. 19, 4\% and in one case the appendix was normal (3.2\%). Of the 16 unprepared abdomen images taken, we had 6 times hydro-aeric levels (19.4\%) and 10 times diffuse grayness (34.2\%). Preoperatively, the diagnosis of appendicular peritonitis was made 23 times (74.2\%), appendicular abscess 7 times (22.6\%) and the diagnosis of occlusion once. The midline supra and subumbilical laparotomy was the most common route in 24 cases (77.4\%). In 7 cases the incision at Mac Burney's point was subsequently widened. An appendectomy plus washing and drainage were performed.

The pus collected and the operative parts were sent for anatomy pathology. The germs encountered were: Escherichiacoli5 cases (33.3\%), Serratiae 1 case (6.7\%) and Staphylococcus aureus 1 case (6.7\%) In 8 cases (53.3\%) the culture was sterile. The antibiograms performed showed 100\% sensitivity of Escherichia coli, Seratiae and Staphylococcus aureus to cephalosporins and macrolides, $100 \%$ resistance to amoxicillin and to ampicillin at what percentage.

The consequences were simple in 23 cases or $74.2 \%, 5$ cases of morbidity or $16.1 \%$ (4 superficial wall suppurations, and one digestive fistula), and 3 cases of death or $9.7 \%$.

\section{Comments}

The frequency of appendicular peritonitis was $19.25 \%$ in our study. It does not differ statistically from that found in the African series by Chavda [9] in Kenya, Koumaré [11] in Mali and Flum [7] in the USA, Marudanayaagam [12], despite the delay in consultation and insufficient health coverage (Table 2). Our consultation time of 5.7 days does not differ from that observed in the African series

Table 1. The most common physical signs.

\begin{tabular}{ccc}
\hline Decreased abdominal breathing & 6 & 19.3 \\
Localizeddefense & 6 & 19.4 \\
Contracture & 25 & 80.6 \\
Abdominal dullness & 19 & 61.3 \\
Abdominal silence & 20 & 64.5 \\
Bulging and painful douglas & 14 & 45.2 \\
Painful Douglas & 17 & 54.8 \\
\hline
\end{tabular}


Table 2. The rate of peritonitis according to the authors (authors too old).

\begin{tabular}{lccccc}
\hline \multicolumn{5}{c}{ Chavda Kenya Flum USA Koumaré Mali } & \multicolumn{2}{c}{ Marudanay } & \multirow{2}{*}{ Nous 2017 } \\
& $2005[9]$ & $2001[7]$ & $1995[11]$ & Angleterre 2006 [12] & \\
\hline $\begin{array}{c}\text { Appendicitis } \\
\text { Appendicular }\end{array}$ & 189 & 63,707 & 109 & 1718 & 112 \\
peritonitis \% & & & & & \\
Statistical test & 29.7 & 25.85 & 28.5 & 13.9 & 27.67 \\
& $\mathrm{P}=0.6760$ & $\mathrm{P}=0.6587$ & $\mathrm{P}=0.8997$ & $\mathrm{P}=0.00003$ &
\end{tabular}

Table 3. Germs according to the authors.

\begin{tabular}{cccc}
\hline & Jasme K Togo 1990 [1] & Dembélé B Mali 2005 [13] & Nous 2017 \\
\hline E. coli & $1^{\mathrm{er}}$ & $1^{\mathrm{er}}$ & $1^{\mathrm{er}}$ \\
Klebsiela & $2^{\mathrm{e}}$ & $2^{\mathrm{e}}$ & $3^{\mathrm{e}}$ \\
Enterobacter & $3^{\mathrm{e}}$ & - & - \\
Streptococus & - & - & - \\
P aeruginosa & - & $3^{\mathrm{e}}$ & $2^{\mathrm{e}}$
\end{tabular}

of Harouna in Niger [14] and Dembélé of Mali [13] which was on average between 4.5 and 7 days against one day in the series. Faniez French [15] with a $\mathrm{p}=$ 0.038 . This statistically significant difference could be explained by the practice of self-medication and the traditional treatments received before admission. We found germs at different rates depending on the study. These are the germs known in surgery (Table 3). The two cases of sterile pus could correspond to perforations following a parasitic appendicitis, since we did not look for these germs. Although rare, some authors have described bilharzian appendicitis in South Saharan Africa [14].

The therapeutic management was resuscitation for 1 to 2 hours before the operation and continued postoperatively. It was based on electrolyte rebalancing plus a triple antibiotic therapy combining a betalactamine, an aminoglycoside and an imidazole. We had to modify this treatment depending on the results of the antibiogram and the clinical course. Most of the germs isolated in our department were sensitive to these molecules. Median laparotomy was the most common route performed in $91.3 \%$ of cases as in other studies [16] [17].

The mesocoeliac position, which is not reported by many authors, was found in $7.4 \%$ of cases. This position was responsible for the occlusive forms in our study. This is confirmed in the literature [18]. The preferred area for perforation was the top (distal part) of the appendix in 125 cases, i.e. $91.24 \%$ against 4 times (2.92\%) the middle part and twice $(1.46 \%)$ at the level from the base. We observed 6 cases of appendicular necrosis, i.e. 4.38\%. Harouna in Niger [10] reported $4 \%$. So the question arises, if the perforation has no other causes than the vascularization.

All the authors are unanimous on the eradication of the infectious focus, the fight against infection and the assurance of fluid and electrolyte balance [15] [16].

The operative technique was based on appendectomy, toilet and peritoneal 
drainage. This drainage is questionable for certain European authors [15] [16]. The consequences were simple in the majority of cases, but we had $15.3 \%$ of morbidity which does not differ statistically from those of other African and European authors [10] [13] [19]. The mortality from acute peritonitis varies according to the aetiology. In the African series it varied between $0.7 \%$ and $17.9 \%$, against $0 \%$ in Belgium [19]. This could be explained by the elevation of the Mannheim peritonitis index score in African studies [13] [20] and the low use of laparoscopic surgery.

\section{Conclusion}

Appendicular peritonitis is a complication of acute appendicitis. It is frequent and morbid. Mortality remains high despite advances in medicine. The introduction of laparoscopic surgery would improve morbidity in African countries.

\section{Conflicts of Interest}

The authors declare no conflicts of interest regarding the publication of this paper.

\section{References}

[1] James, K. and Ahouangbevi, A. (1990) Netilmicine in Surgical Infections at Lomé University Hospital. Medecine from Black Africa, 37, 704-707.

[2] Arc, A. and Hay, J.M. (1986) Peritonitis Caused by Gastrointestinal Perforation. Rev Prat, 36, 1059-1066.

[3] Cissé, B. (2003) Digestive Perforations in the General and Pediatric Surgery. [These] Medicine, No. 54, Departments of the CHU GabrielTouré, Bamako.

[4] Roseau, G. and Marc, F. (1989) Acute Non-Traumatic Abdomen Outside the Postoperative Period. Encyclopédie Medico-Chirurgicale, 9042 A10, 8

[5] Ohmann, C., Franke, C., Kraemer, M. and Yang, Q. (2002) Neues Zur Epidemiologic der akutenappendicitis. Der Chirurg, 73, 769-776. https://doi.org/10.1007/s00104-002-0512-7

[6] Lau, W.Y., Fan, S.T., Yiu, T.F., Chu, K.W. and Lee, J.M. (1985) Acute Appendicitis in the Elderly. Surgery, Gynecology \& Obstetrics, 161, 157-160.

[7] Flum, D.R., Morris, A., Koepsell, T. and Dellinger, E.P. (2001) Has Misdiagnosis of Appendicitis Decreased over Time? A Population-Based Analysis. JAMA, 286, 1748-1753. https://doi.org/10.1001/jama.286.14.1748

[8] Kraemer, M., Kraemer, K., Leppert, R. and Acute Abdominal Pain Study Group. (1999) Perforating Appendicitis: Is It a Separate Disease? European Journal of Surgery, 165, 481-482. https://doi.org/10.1080/110241599750006730

[9] Chavda, S.K., Hassan, S. and Magoha, G.A.O. (2005) Appendicitis at Kenyatta National Hospital, Nairobi. East African Medical Journal, 82, 527-531. https://doi.org/10.4314/eamj.v82i10.9351

[10] Harouna, Y., et al. (2005) Generalized Appendicular Peritonitis in 70 Cases at the Niamey National Hospital. Communication Scientifique ACAF, Bamako.

[11] Koumaré, A.K., Traoré, T., Ongoiba, N. and Traoré, A.K. (1995) Appendectomy in Bamako. Annales de Chirurgie, 2, 188-191. 
[12] Marudanayagam, R. and Williams, G.T. (2006) Review of the Pathological Results of 2660 Appendectomy Specimens. Journal of Gastroenterology, 41, 745-749. https://doi.org/10.1007/s00535-006-1855-5

[13] Dembelé, B. (2005) Acute Generalized Peritonitis in the General and Pediatric Surgery, Departments of the Gabriel Touré University Hospital in Bamako, Concerning 200 Cases. [Thesis] Medicine, No. 215, Bamako.

[14] Kuadio, A. (1980) Contribution to the Study of Appendicular Peritonitis in Connection with 100 Cases at the University Hospital of Treichville. [Thesis] Medicine, No. 686, RCI, Abidjan.

[15] Faniez, P.L., Koffi, E. and Panis, Y. (1992) Appendicular Peritonitis. Revue du praticien, 42, 706-710

[16] Flamant, Y. (1994) Complications of Acute Appendicitis. Revue du praticien, 44, 2231-2235.

[17] Barbier, J. and Carretier, M. (1988) Acute Peritonitis. Encyclopedie Medico-Chirugicale Urgences, B10, 18.

[18] Coulibaly, M. (2002) Acute Appendicitis in the General and Pediatric Surgery. [These] Medicine, No. 44, Department of the Gabriel Touré Hospital. Bamako.

[19] Navez, B., Tasseti, V., Scohy, J.J., Mutter, D., Guiot, P., Evrard, S., et al. (1998) Laparoscopic Management of Acute Peritonitis. British Journal of Surgery, 85, 32-36. https://doi.org/10.1046/j.1365-2168.1998.00531.x

[20] Bruch, H.P., Woltmann, A. and Eckman, C. (1999) Surgical Management of Peritonitis and Sepsis. EntralblChirurg, 124, 176-180. 